\title{
The Influence of Behavioral Counseling Theory with the Technique of Modeling Setting Lesson Study on Self Endurance Class X Students Accommodation in Hospitality 5 Public High School 2 Singaraja
}

\section{Pengaruh Teori Konseling Behavioral Dengan Tehnik Modeling Setting Lesson Study Terhadap Self Endurance Siswa Kelas X Akomodasi Perhotelan 5 Smk Negeri 2 Singaraja}

\author{
I Kd Bgs Raka Novta Adi Putra, Ni Ketut Suarni,I Ketut Dharsana \\ Universitas Pendidikan Ganesha \\ e-mail: dedekxnanda@gmail.com
}

\author{
Received \\ Revised \\ Accepted \\ Published Online
}

\section{Conflict of Interest} Disclosures:

The authors declare that they have no significant competing financial, professional or personal interests that might have influenced the performance or presentation of the work described in this manuscript.

\begin{abstract}
This study aims to determine the effect of Behavioral Counseling Theory with the Modeling Setting Lesson Study Technique on Self Endurance. This type of research is Quasi Experiment, with the design of Non Equvalent Pree Postest Only Control Group Design, the sample of this study was taken by using random sampling techniques. The subjects of this study were 35 students in class X Hospitality Accommodation 5 at Singaraja State Vocational High School 2. The process of retrieving data in this study uses the method of observation, interviews, diaries and the Self Endurance questionnaire on the linkert scale pattern. Data were analyzed descriptively and statistical analysis using the t-test formula. Based on the value of the $t$ test above, it is obtained thit of 19.34 with ttab of 1.66 at the significance of 0.05 . So that it can be concluded $\mathrm{H} 1$ is accepted. So the results of the study show that Behavioral Counseling with the Modeling Technique through Lesson Study has an effect on Self Endurance students
\end{abstract}

Keywords: behavioral counseling, modeling, self endurance

\begin{abstract}
Abstrak: Penelitian ini bertujuan untuk mengetahui Pengaruh Teori Konseling Behavioral Dengan Tehnik Modeling Setting Lesson Study Terhadap Self Endurance. Jenis penelitian ini adalah Quasi Eksperiment, dengan desain Non Equvalent Pree Postest Only Control Group Design, sampel penelitian ini diambil dengan dengan tehnik random sampling. Subjek penelitian ini sebanyak 35 orang siswa kelas X Akomodasi Perhotelan 5 di SMK Negeri 2 Singaraja. Proses pengambilan data dalam penelitian ini menggunakan metode observasi, wawancara, buku harian dan kuesioner Self Endurance pola skala linkert. Data dianalisis secara deskriptif dan analisis statistik dengan rumus t-test. Berdasarkan nilai uji $t$ di atas diperoleh $t_{\text {hit }}$ sebesar 19,34 dengan $t_{\text {tab }}$ sebesar 1,66 pada signifikansi 0,05. Sehingga dapat disimpulkan H1 diterima. Jadi hasil penelitian menunjukan Konseling Behavioral dengan Teknik Modeling melalui Lesson Study berpengaruh terhadap Self Endurance siswa
\end{abstract}

Kata Kunci: Konseling Behavioral, Modeling, Self Endurance 


\section{PENDAHULUAN}

\section{PENDAHULUAN}

Pendidikan merupakan suatu bidang yang memiliki peranan yang sangat sentral dalam kehidupan manusia pada suatu Negara. Keberhasilan suatu Negara sangat ditentukan oleh penyelenggaran pendidikannya. Pendidikan haruslah terorganisir dan terkoordinasi dengan struktur kelembagaan akurat yang sangat mengharapkan dapat menciptakan sumber daya manusia berkualitas melalui upaya peningkatan mutu pendidikan. Guru dan siswa merupakan dua subjek yang berperan pada kegiatan pembelajaran. Pembelajaran merupakan proses terjadinya interaksi antara guru dan siswa, siswa dan siswa serta siswa dan lingkungannya. Dari hasil belajar ini nantinya siswa diharapkan membentuk perilaku ataupun sikap yang mencerminkan tahan terhadap suatu rintangan ataupun berbagai cobaan yang diperoleh ketika menjalani proses pembelajaran di sekolah dan juga menjalani keseharian mereka dalam berbagai aktivitas. saat pelaksanaan observasi di lapangan banyak ditemukan sebuah fenomena atau kejadian yang melibatkan peserta didik dalam mengikuti proses pembelajaran di dalam kelas dimana terdapat siswa yang mampu untuk menyelesaikan berbagai macam kewajiban yang ia dapatkan dan selalu bekerja keras dengan tugas yang dia peroleh. Kemudian terdapat juga terdapat siswa yang kurang mampu menyelesaikan suatu pekerjaan sampai selesai.

\section{Self Endurance}

Self Endurance menurut Darsana (2010) adalah kebutuhan untuk tahan mengatasi rintangan meliputi mengerjakan pekerjaan sampai selesai, berusaha tekun menghadapi pekerjaan, bekerja keras pada suatu tugas. Berdasarkan definisi tersebut maka dapat diambil 3 indikator yang meliputi :

1) Mengerjakan pekerjaan sampai selesai adalah kepribadian yang dimiliki oleh seseorang untuk selalu bisa mengerjakan pekerjaan, tugas-tugas, dan apapun itu sampai selesai dan mendapatkan hasil yang semaksimal mungkin,dimana dalam keseharian terdapat pula siswa tidak mampu untuk mengerjakan tugas hingga selesai lantaran didera rasa malas

2) Berusaha tekun menghadapi pekerjaan adalah kepribadian yang dimiliki oleh seseorang untuk selalu tetap berusaha dalam menyelesaikan tugas-tugas dan tidak selalu merasa malas jika mendapatkan tugastugas dan ada juga fenomena dimana siswa tidak tekun dalam kewajiban yang ia terima dalam proses pembelajaran

3) Bekerja keras pada suatu tugas adalah kepribadian yang dimiliki oleh seseorang untuk selalu mau bekerja keras dengan tugas-tugas yang di dapatkan dan tidak mudah menyerah tetapi terdapat pula yang sama sekali suatu pola berpikir bekerja keras dalam menghadapi suatu kewajiban misalkan lalai jika diberikan sebuah tugas

\section{Konseling Behavioral}

Konseling Behavioral merupakan suatu metode dengan mempelajari tingkah laku tidak adatif melalui proses belajar yang normal. Tingkah laku tersusun dari respon kognitif, motorik dan emosional yang dipandang sebagai respon terhadap stimulus eksternal dan internal dengan tujuan memodifikasi koneksikoneksi dengan metode stimulus respon sedapat mungkin. Gerald Corey (1988:197) menyatakan bahwa konseling behavioral adalah konseling yang berurusan dengan perubahan tingkah laku kearah yang lebih adatif serta studinya terbatas pada pengamatan dan perubahan tingkah laku. Atau dengan kata lain, konseling behavioral adalah proses membantu individu untuk belajar tentang bagaimana mengatasi atau menyelesaikan masalah-masalah interpersonal, kecemasan merupakan salah satu emosional sehingga mampu mengambil keputusan guna menciptakan kondisi-kondisi baru untuk belajar. Adapun langkahlangkah konseling behavioral adalah sebagai berikut (gantina komalasari, eka wahyuni, 2016) adalah sebagai berikut : 1) Melakukan Asesmen (assessment). Tahap ini bertujuan untuk menentukan apa yang dilakukan oleh konseli pada saat ini. 2) Menetapkan tujuan (goal setting). Konselor dan konseli menentukan tujuan konseling sesuai dengan kesepakatan bersama berdasarkan informasi yang telah disusun dan dianalisis. 3) Implementasi teknik (technique implementation). Setelah tujuan konseling dirumuskan, konselor dan konseli menentukan strategi belajar yang terbaik untuk membantu konseli 
mencapai perubahan tingkah laku yang diinginkan. 4) Evaluasi dan pengakhiran (evaluation-termination). Evaluasi konseling behavioral merupakan proses yang berkesinambungan.evaluasi dibuat atas dasar apa yang jkonseli perbuat.Tingkah laku konseli digunakan sebagai dasar untuk mengevaluasi evektivitas konselor dan efektivitas tertentu dari teknik yang digunakan.

\section{Tujuan Konseling Behavioral}

Tujuan konseling behavioral adalah membantu klien untuk mendapatkan tingkah laku baru. Dasar alasannya adalah bahwa segenap tingkah laku adalah dipelajari (learned), termasuk tingkah laku maladaptive (salah usai). Jika tingkah laku neurotik learned, maka ia bisa unlearned (dihapus dari ingatan)Konseling behavioral pada hakikatnya terdiri atas proses penghapusan hasil belajar yang tidak adaptif dan pemberian pengalaman-pengalaman belajar yang didalamnya respon-respon yang layak yang belum dipelajari. (Corey, 2010 : 199) Dari tujuan diatas dapat dibagi menjadi beberapa sub tujuan yang lebih konkrit yaitu:

1. Membantu klien untuk menjadi asertif dan mengekspresikan pemikiran-pemikiran dan hasrat-hasrat ke dalam situasi yang membangkitkan tingkah laku asertif (mempunyai ketegasan dalam bertingkah laku).

2. Membantu klien menghapus ketakutan-ketakutan yang tidak realistis yang menghambat dirinya dari keterlibatan peristiwa-peristiwa sosial.

3. Membantu untuk menyelesaikan konflik batin yang menghambat klien dari pembuatan pemutusan yang penting bagi hidupnya.

Adapun tujuan khusus dari konseling behavioral adalah membantu klien menolong diri sendiri, mengembalikan klien ke dalam masyarakat, meningkatkan keterampilan sosial, memperbaiki tingkah laku yang menyimpang, membantu klien mengembangkan sistem self management dan self control. (Sutarno, 2003 : 8) Sehingga tujuan dari konseling behavioral adalah membentuk perilaku baru yang adaptif melalui proses belajar dan lingkungan.

\section{Tehnik Modelling}

Menurut Dharsana (2016) teknik modeling adalah cara untuk memperkenalkan dan konselor menyediakan model yang memiliki self endurance tinggi untuk dapat melakukan hal itu, siswa di suruh untuk meniru model yang telah disediakan oleh konselor. Sejalan dengan definisi tersebut, "Komalasari, dkk. (2014:176) mengemukakan teknik modeling adalah cara yang digunakan oleh konselor untuk meningkatkan self endurance melalui penokohan, penokohan yang dimaksud seperti penokohan melalui film, tokoh imajinasi (imajiner), dan lain sebagainya". Modeling juga disebut peniruan (imitation), yaitu menunjukan bahwa perilaku orang lain yang diamati, ditiru, lebih merupakan peniruan terhadap apa yang dilihat dan diamati. Proses belajar melalui pengamatan menunjukan terjadinya proses belajar setelah mengamati perilaku pada orang lain. Menurut Komalasari, dkk. (2014:176), Teknik modeling adalah cara yang digunakan oleh konselor untuk meningkatkan Self Endurance melalui penokohan, penokohan yang dimaksud seperti penokohan melalui film, tokoh imajinasi (imajiner), dan lain sebagainya. Modeling juga disebut peniruan (imitation), yaitu menunjukan bahwa perilaku orang lain yang diamati, ditiru, lebih merupakan peniruan terhadap apa yang dilihat dan diamati. Proses belajar melalui pengamatan menunjukan terjadinya proses belajar setelah mengamati perilaku pada orang lain. adalah cara yang digunakan oleh konselor untuk meningkatkan Self Endurance melalui penokohan, penokohan yang dimaksud seperti penokohan melalui film, tokoh imajinasi (imajiner), dan lain sebagainya. Modeling juga disebut peniruan (imitation), yaitu menunjukan bahwa perilaku orang lain yang diamati, ditiru, lebih merupakan peniruan terhadap apa yang dilihat dan diamati. Proses belajar melalui pengamatan menunjukan terjadinya proses belajar setelah mengamati perilaku pada orang lain.

\section{Lesson Study}

Lesson study adalah suatu pendekatan peningkatan kualitas pembelajaran yang awal mulanya berasal dari Jepang.Kata atau istilah Jepang untuk ini adalah "Jugyokenkyu" (Dharsana 2017:220,Yoshida, 1999 dalam Lewis, 2002). Lesson Study adalah suatu bentuk utama peningkatan kualitas pembelajaran dan pengembangan keprofesionalan guru yang dipilih oleh guru-guru Jepang. 
Dalam melaksanakan Lesson Study, guru-guru secara kolaboratif 1. mempelajari kurikulum, dan merumuskan tujuan pembelajaran dan tujuan pengembangan siswanya (pengembangan kecakapan hidupnya), 2. merancang pembelajaran untuk mencapai tujuan tersebut, 3. melaksanakan dan mengamati suatu research lesson ("pembelajaran yang dikaji") untuk kemudian 4. melakukan refleksi untuk mendiskusikan pembelajaran yang dikaji dan menyempurnakannya, dan merencanakan pembelajaran berikutnya. Menurut Styler dan Hiebert (dalam Sparks, 1999) Lesson Study adalah suatu proses kolaboratif di mana sekelompok guru mengidentifikasi suatu masalah pembelajaran, merancang suatu scenario pembelajaran (yang meliputi kegiatan mencari buku dan artikel mengenai topik yang akan dibelajarkan), membelajarkan siswa sesuai skenario (salah seorang guru melaksanakan pembelajaran sementara yang lain mengamati), mengevaluasi dan merevisi skenario pembelajaran, membelajarkan lagi skenario pembelajaran yang telah direvisi, mengevaluasi lagi pembelajaran dan membagi hasilnya dengan guru-guru lain (mendiseminasikannya). Berdasarkan pendapat ahli diatas maka dapat disintesiskan lesson study merupakan suatu proses pembelajaran dimana guru merancang sebuah skenario pembelajaran, sementara yang lainnya mengamati, mengevaluasi dan merevisi scenario pembelajaran lalu mempraktekan kembali scenario pembelajaran yang telah direvisi.

\section{METODE PENELITIAN}

Jenis penelitian yang digunakan dalam penelitian ini adalah rancangan penelitian "eksperimen semu (Quasi eksperiment)" Design nonequivalent dengan pretest-postest control group design" hal ini dikarenakan peneliti melakukan perlakuan (treatment) terhadap suatu Kelas dan dilakukan suatu prestest sebelum perlakuan diberikan

Dari data awal yang diperoleh, sebagian siswa menunjukkan Self Endurance yang rendah dalam penerapan Self Endurance maka dari itu peneliti berusaha meningkatkan Self Endurance siswa dengan menerapkan konseling behavioral dengan teknik latihan modeling. Siswa nantinya dapat dilatih untuk memerankan tokoh-tokoh yang mempunyai Self Endurance yang tinggi disamping itu pula dengan adanya tehnik modeling ini siswa juga dapat menyimak tokoh yang mempunyai Self Endurance yang tinggi disana lah mereka nantinya dapat memetik suatu hikmat tentang bagaimana kah pentingnya memiliki Self Endurance karena apabila sudah mempunyai Self Endurance maka jalan mereka untuk menggapai kesuksesan bukanlah suatu hal yang mustahil. Siswa tentunya sangat perlu banyak belajar dari orang-orang sukses yang meraih impiannya dengan penuh tekad dan juga kerja keras. Penelitian ini mengambil jumlah sampel siswa yang menunjukkan kriteria Self Endurance sedang maupun rendah sebanyak 35 orang siswa.

Untuk mengumpulkan data tentang Self Endurance siswa dan untuk memperoleh data yang akurat maka dalam penelitian ini menggunakan beberapa teknik pengumpulan data beserta masingmasing perangkat pengumpulan datanya yaitu: (1) Observasi, (2) Wawancara, (3) Kuisioner, (4) Buku Harian.

\section{HASIL DAN PEMBAHASAN}

Data yang digunakan dalam penelitian ini di dapatkan dari data hasil penyebaran kuisioner Self Endurance pada kelas eksperimen yaitu kelas X Akomodasi perhotelan 5 dan juga kelas kontrol yaitu kelas X Akomodasi perhotelan 3 dengan mengambil tahap preetest dan juga postest. Kemudian data pretes dan postes dari hasil kuisioner tersebut di analisis dengan uji-t untuk mencari perbedaan antara postes eksperimen dan postes kontrol. Proses perhitunganuji-t dalam penelitian ini menggunakan aplikasi JASP 10.0.

\section{Uji-t}

Untuk mengukur perbedaan antara data kelas kontrol dan kelas eksperimen dalam penelitian ini digunakan uji-t. Berdasarkan uji-t yang dilaksanakan peneliti didapatkan $t_{\text {hit }}$ sebesar 19,34 dengan signifikansi $<0.05$ Uji T dilaksanakan dengan menggunakan perhitungan manual yaitu dengan menggunakan orek-orek kertas. Dengan rincian seperti yang diuraikan di bawah ini pada tabel 1 
Tabel 1. Hasil Perhitungan data dengan menggunakan Aplikasi JASP 10.0

Independent Samples T-Test

\begin{tabular}{lrrr}
\hline & $\mathbf{t}$ & df & p \\
\hline y1 & 3.671 & 69.00 & $1.000^{\mathrm{a}}$ \\
$\mathrm{y} 2$ & 19.346 & 69.00 & $1.000^{\mathrm{a}}$ \\
\hline
\end{tabular}

Note. Student's T-Test.

${ }^{a}$ Levene's test is significant $(\mathrm{p}<.05)$, suggesting a violation of the equal variance assumption

Dengan demikian dalam penelitian ini $\mathrm{H}_{0}$ yang berbunyi "Konseling Behavioral dengan Teknik Modeling Setting Lesson study tidak berpengaruh pada Self Endurance siswa kelas X Akomodasi perhotlan 5" dinyatakan ditolak. Sedangkan $\mathrm{H}_{\mathrm{a}}$ yang berbunyi "Konseling Behavioral dengan Teknik Modeling Setting Lesson study berpengaruh pada Self Endurance siswa kelas X Akomodasi perhotelan 5" dinyatakan diterima.

\section{PENUTUP}

\section{Kesimpulan}

Berdasarkan hasil penelitian dan pembahasan, maka dapat diuraikan simulan penelitian yaitu sebagai berikut.

Terdapat pengaruh Self Endurance antara siswa kelas X Akomodasi perhotelan 5 yang mengikuti konseling dengan teknik modeling dan yang tidak menerima treatment di SMK Negeri 2 Singaraja. Dengan melakukan treatment yaitu konseling behavioral dengan teknik modeling dalam meningkatkan Self Endurance siswa secara signifikan.

\section{Saran}

Berdasarkan hasil penelitian dan pemabahasan, maka dapat diajukan beberapa saran, guna peningkatan dan pengembangan Self Endurance, yaitu sebagi berikut.

1. Bagi guru pembimbing atau konselor sekolah hendaknya dalam pemberian layanan bimbingan konseling kepada siswa terlebih dahulu memperhatikan hasil need assessment siswa, sehingga akan lebih mudah memberikan layanan kepada siswa sesuai dengan kebutuhan atau permasalahan yang sedang dialami oleh siswa. Selain itu diharapkan agar konselor lebih terampil dalam menangani permasalahan konseli serta diharapkan penangan masalah dilakukan dengan memberikan teknik konseling yang tepat sesuai dengan masalah yang dihadapi siswa, dimana agar penanganan masalah siswa lebih efektif dan efisien. Guru pembimbing di sekolah agar lebih sering menggunakan teknik latihan asertif dalam melaksanakan layanan konseling kelompok khususnya dalam usaha meningkatkan Self Endurance karena apabila siswa sudah mempunyai Self Endurance yang baik maka jalan mereka untuk menuju kesuksesan akan amat lebar

2. Bagi Kepala Sekolah, sebagai kepala manajemen sekolah hendaknya memberikan dukungan dan dorongan kepada guru pembimbing atau konselor sekolah dalam merencanakan pelayanan 
bimbingan dan konseling dalam upaya memfasilitasi siswa dalam upaya peningkatan Self Endurance yang merupakan faktor-faktor pendukung dari dalam diri peserta didik yang sangat menentukan keberhasilan peserta didik dalam meraih prestasi belajar yang optimal dan bahkan memberikan kontribusi yang besar bagi kesuksesan seseorang dalam kehidupannya di masa mendatang.

3. Bagi peneliti bidang bimbingan dan konseling yang lainnya, diharapkan agar lebih mengembangkan lagi penelitian-penelitian serupa demi tercapainya perkembangan siswa secara optimal karena penelitian ini masih memiliki beberapa kekurangan seperti ketebatasan waktu penelitian yang ada

\section{DAFTAR PUSTAKA}

Ayu Km Kurnia Dwi Armasari1, Nym Dantes2, M. S. (2013). Penerapan Model Konseling Behavioral Dengan Teknik Deayu Km Kurnia Dwi Armasari1, Nym Dantes2, M. S. (2013). Penerapan Model Konseling Behavioral Dengan Teknik Desensitisasi Sistematis Untuk Meminimalisasi Tingkat Kecemasan Dalam Proses Pembelajaran Siswa

Amelia, T., Indriyanti, R. D., Jurusan, S., Informasi, S., Surabaya, S., \& Epps, I. (2016). Pengembangan Aplikasi Tes Kerpibadian Menggunakan Metode Edward 'S Personal Preference Schedule ( Epps ), 1-3. Retrieved from http://sir.stikom.edu/724/1/2010-OSIT04.pdf

Antari, N. M. S., Suarni, N. K., \& Sulastri, M. (2013). Penerapan Konseling Behavioral Teknik Asertif Untuk Meminimalisir Munculnya Perilaku Prokrastinasi Akademik Kelas X 4 Sma Laboratorium Undiksha. Retrieved from http://ejournal.undiksha.ac.id/index.php/JJBK/article/download/771/644

Ardana, I. N. S., Dharsana, I. K., \& Suranata, K. (2014). Penerapan Konseling Karir Holland Dengan Teknik Modeling Untuk Meningkatkan Kematangan Karir Siswa Kelas X Tkj 1 Smk Negeri 3 Singaraja. E-Jurnal Undiksa Jurusan Bimbingan Dan Konseling, 2(1). Retrieved from https://ejournal.undiksha.ac.id/index.php/JJBK/article/viewFile/3924/3137

Bandura, A. (1999). Social cognitive theory : An agentic Albert Bandura. Asian Journal of Social Psychology, 2(1), 21-41. https://doi.org/10.1111/1467-839X.00024

Bandura, a, Barbaranelli, C., Caprara, G. V, \& Pastorelli, C. (2008). ( Perspektif Teori Kognitif Sosial dan Implikasinya terhadap Pendidikan ) Abd . Mukhid. Child Development, 72(1), 187-206. Retrieved from http://www.ncbi.nlm.nih.gov/pubmed/15350854

Baranova, S., \& Kal k ke, B. (2012). Docē tā jiem Nepieciešamās Kompetences Pedagoǵ ijas Studentu Skatī jumā Competences needed for the university faculty in view of pedagogy $\begin{array}{lllll}\text { students, } & \text { I, 205-216. } & \text { Retrieved }\end{array}$ http://journals.rta.1v/index.php/SIE/article/viewFile/41/39

Benight, C. C., \& Bandura, A. (2004). Social cognitive theory of posttraumatic recovery: the role of perceived self-efficacy. Behaviour Research and Therapy, 42, 1129-1148. https://doi.org/10.1016/j.brat.2003.08.008

Chu, S. S. D., \& Ho, C. V. (1995, March 21). Self-recovering erase scheme to enhance flash memory endurance. Google Patents. https://patents.google.com/patent/US5400286A/en

Dharsana, K. (2013). Teori-Teori Konseling (Diktat). Singaraja: Jurusan Bimbingan Konseling Fakultas Ilmu Pendidikan Universitas Pendidikan Ganesha.

Edward, T. M. (1959). Personal preference schedule. New York: The Psychological Corporation. Retrieved from https://scholar.google.co.id/scholar?hl=id\&as_sdt=0\%2C5\&q

Jamner, L. D., \& Schwartz, G. E. (1986). Self-deception predicts self-report and endurance of pain. Psychosomatic Medicine. https://insights.ovid.com/crossref?an=00006842-198603000-00006

Kurniawan, H., \& Istiningrum, A. A. (2012). Penerapan metode pembelajaran kooperatif teknik think pair share untuk meningkatkan motivasi belajar akuntansi kompetensi dasar menghitung mutasi dana kas kecil siswa kelas X Akuntansi 2 SMK Negeri 7 Yogyakarta tahun ajaran 2011/2012. Jurnal Pendidikan Akuntansi Indonesia, 10(1). Retrieved from https://journal.uny.ac.id/index.php/jpakun/article/view/925

Putri, E. (2010). Minat berwirausaha siswa SMk Triguna utama Ciputat Tangerang Selatan dilihat 
dari status pekerjaan oran tua. Retrieved from http://repository.uinjkt.ac.id/dspace/handle/123456789/1109

Paradigma, J. (2012). Teori dan Aplikasi Pendekatan Behavioristik dalam Konseling Abstrak Pendahuluan Teori dan Pendekatan Behavioristik, (14), 1-11.

Rola, F. (2006). Hubungan konsep diri dengan motivasi berprestasi pada remaja. Retrieved from http://repository.usu.ac.id/handle/123456789/1938

Saraswati, K. A., Dantes, N., \& Sulastri, M. (2013). Penerapan konseling behavioral teknik penguatan positif untuk meningkatkan keterampilan berkomunikasi antar pribadi siswa.

Jamner, L. D., \& Schwartz, G. E. (1986). Self-deception predicts self-report and endurance of pain. Psychosomatic Medicine. https://insights.ovid.com/crossref?an=00006842-198603000-00006

Sumarmo, U., Hidayat, W., Zukarnaen, R., Hamidah, \& Sariningsih, R. (2012). Kemampuan dan Disposisi Berpikir Logis, Kritis, dan Kreatif Matematik. Jurnal Pengajaran MIPA, 17, 17-33. https://doi.org/10.18269/jpmipa.v17i1.228

Sutama, G. A., Suranata, K., \& Dharsana, K. (2014). Modeling Untuk Meningkatkan Kemandirian Belajar Siswa Kelas Ak C Smk Negeri 1 Singaraja. E-Journal Undiksa Jurusan Bimbingan Konseling, 2(1).

Sutarjo, I. E., Wmp, D. A., \& Suarni, N. K. (2014). Gym Untuk Menurunkan Burnout Belajar Pada Siswa Kelas VIII SMP LABORATORIUM UNDIKSHA SINGARAJA Tahun perbedaan efektivitas antara kelompok konseling behavioral teknik relaksasi dengan brain gym untuk menurunkan burnout belajar, ini dilihat dari hasil ana, (1).

Usdiyana, D., Purniati, T., Yulianti, K., \& Harningsih, E. (2009). Meningkatkan Kemampuan Berpikir Logis Siswa SMP Melalui Pembelajaran Matematika Realistik. Jurnal Pengajaran MIPA, 13(1), 1-14. https://doi.org/10.1017/CBO9781107415324.004

Weinberg, R. S., Smith, J., Jackson, A., \& Gould, D. (1984). Effect of association, dissociation and positive self-talk strategies on endurance performance. Canadian Journal of Applied Sport Sciences. https://psycnet.apa.org/record/1985-00646-001

Yani, \& Dharsana. (2014). Penerapan Konseling Behavioral Dengan Teknik Modeling Untuk Meningkatkan Proaktif Siswa Kelas X BB SMA Negeri 2 Singaraja. Jurnal Ilmiah Bimbingan Konseling, 2(1). Retrieved from https://ejournal.undiksha.ac.id/index.php/JJBK/article/view/372Agustin, M. (2014). Hakikat Bimbingan dan Konseling untuk Anak Usia Dini. Modul, 1, 1-31. Retrieved from http://repository.ut.ac.id/4716/1/PAUD4406-M1.pd

Article Information (Supplementary)

$\begin{array}{ll}\text { Conflict of Interest Disclosures: } & \begin{array}{l}\text { The authors declare that they have no significant competing } \\ \text { financial, professional or personal interests that might have } \\ \text { influenced the performance or presentation of the work described } \\ \text { in this manuscript. }\end{array} \\ \text { Copyrights Holder: <authors }>\text { <year }> & \begin{array}{l}\text { First Publication Right: BISMA The Journal of } \\ \text { Counseling }\end{array} \\ \text { https://doi.org/10.xxx/:xxxx } & \end{array}$

Word Count: 